\title{
Secondary School Mathematics Teachers Perceptions on Continuous Assessment in Guraghe Zone
}

\author{
Lemi Moges Mengesha \\ Department of Mathematics, College of Natural and Computational Science, \\ Wolkite University, Wolkite, Ethiopia \\ Solomon zerfu Degefa \\ Department of Mathematics, College of Natural and Computational Science, \\ Wolkite University, Wolkite, Ethiopia
}

\begin{abstract}
Assessment is a vital instrument for enhancing teaching and learning. Perceptions that teachers have on assessment are likely to influence their assessment practices. This study explored perceptions of secondary school mathematics teachers on assessment. A total of 80 Guraghe Zone mathematics teachers were involved in the study. A questionnaire comprising questions that required establishing demographic information of participants as well as their perceptions on assessment was used. Results show that the overall respondents' perception towards practices of continuous assessment has mean 3.630 and standard deviation 1.210. Perceptions on assessment show that items on the role of assessment in making students concentrate their efforts in learning, making students confident in their final examination and usefulness of feedback in enhancing students' performance were strongly agreed or agreed by a large proportion of the participants.
\end{abstract}

DOI: $10.7176 /$ RHSS/11-1-02

Publication date: January $31^{\text {st }} 2021$

\section{INTRODUCTION}

Assessment refers to the methods used in determining the extent to which students are achieving the intended learning outcomes for a particular course or programme [1], [2]. Assessment is an integral part of teaching and learning which involves the process of gathering, interpreting and recording information related to student progress in learning and the effectiveness of the teaching strategies [3]. It aims at bringing about improvement for both the teacher who is assessing and the students who are being assessed.

According to Popham [4], assessment enables teachers to gather information about the students' progress as well as the extent to which methods of instruction used are helping the students to achieve the intended learning outcomes. Through assessment teachers can explore better ways of supporting students' learning and regulating their teaching strategies. On the other hand, assessment helps the students to know the areas that they need to work hard so as to attain the desirable learning outcomes.

Assessment is used to improve both teaching and learning and is crucial in ensuring the quality of education offered. Assessment can contribute to enhancing quality of education if appropriate decisions and measures are taken based on the information revealed through assessment. However, determining what to assess and how to assess effectively and establishing remedial measures required, is a complex process.

In this respect assessment of student achievement is changing as today's students face a world that demands new knowledge, skills and behaviors' that have not yet been defined [5]. Students, in this fast and ever changing context, need not only develop deep understandings of disciplines but also develop the ability to analyze, synthesize and make inferences as well as think critically and solve problems. Assisting students to develop these knowledge, skills and behaviors' and become life-long learners requires changes in the assessment processes at the school and classroom level.

In relation to school setting, assessment defines as any procedure or activity that is designed to collect information about the knowledge, attitude, or skills of the learner or group of learners [7]. Assessment plays an important role in motivating students' learning and in formation of good study habits. Encouragement and reward of individual efforts would have been difficult if there was no assessment and excellence in achievement would be less demonstrable [6]. So assessment must be an interaction between the teacher and students, with the teacher continually seeking to understand, what a student can do and how a student is able to do it[8].

\section{Statement of the problem}

Learning theory emphasizes learning with understanding. Assessment should be able to reveal the quality of students' understanding and thinking as well as specific content or processes. Frequency of assessment is also considered important in facilitating retention of material learnt. There are various methods that can be used to assess students learning such as portfolios, projects, performance assessment such methods offer rich information about teaching and learning. 
Taking all of these in to account, the MOE in our country Ethiopia introduced continuous assessment at the different level of the educational institutions. To realize this, the role of teachers is of paramount importance. Put it differently, teachers should be well - informed about the concept and procedures of practicing continuous assessment before they are made to implement it. In line with this teachers' knowledge and attitude should be considered for effective implementation of the assessment program [9].

In our context, however, there is no research evidence that tells us about the status of perception of assessment practices that mathematics teachers were used in secondary schools in Guraghe Zone. It is worthwhile, therefore, as part of the investigators it was important to examined mathematics teacher's use of continuous assessment in Guraghe Zone.

\section{Method of the study}

\section{A. Objective of the study}

The study intended to achieve the following objectives:

- To establish teachers' perceptions of assessment.

- To determine whether there are significant differences in teachers' perceptions of assessment by gender.

B. Instrument

The questionnaire developed by the researchers was used. It consisted of items concerning the demographic information of the participants and items concerning teachers' perception of assessment. The items of this questioner include 7 items of questions on perceptions of teachers contain five point scale measurements i.e., strongly agree $=5$, agree $=4$, undecided $=3$, disagree $=2$, strongly disagree $=1$ the instrument was validated by the researchers', supervisor and other lecturers in Wolkite University. Based on the proper study, identification of problem areas and further modifications made, final instrument for the study was drawn up.

\section{Participants and Data Analysis}

The study involved all mathematics teachers of grade 9 and 10 in Guraghe Zone. The marking of items includes teachers from all weredas in a zone. It was therefore considered that the views of the teachers who participated in marking would be a representation of the perceptions of teachers in general. A total of 80 teachers who were requested to participate in the study and the questionnaires were given to them. Returned completed questionnaires were 80. Data were coded accordingly and entered SPSS programme for analysis. Both descriptive statistics such as means and standard deviations as well as inferential statistics, t-test for independent samples were used.

\section{Results of the study}

A. Demographic characteristics of respondents

The demographic information of participants was analyzed to disclose the characteristics of teachers who participated in the study.

Table 1: compositions of participants by their sex

\begin{tabular}{|l|l|r|}
\hline Sex & Frequency & Percent \\
\hline Male & 57 & 71.2 \\
\hline Female & 23 & 28.8 \\
\hline
\end{tabular}

As indicated in the table 1 , out of the 80 participants shows that most of the respondents' $57(71.2 \%)$ are males and few of them $23(28.8 \%)$ are females. these indicates that females are not interested and more encouraged to join and study mathematics.

Figure 1: Composition of participants by age category.

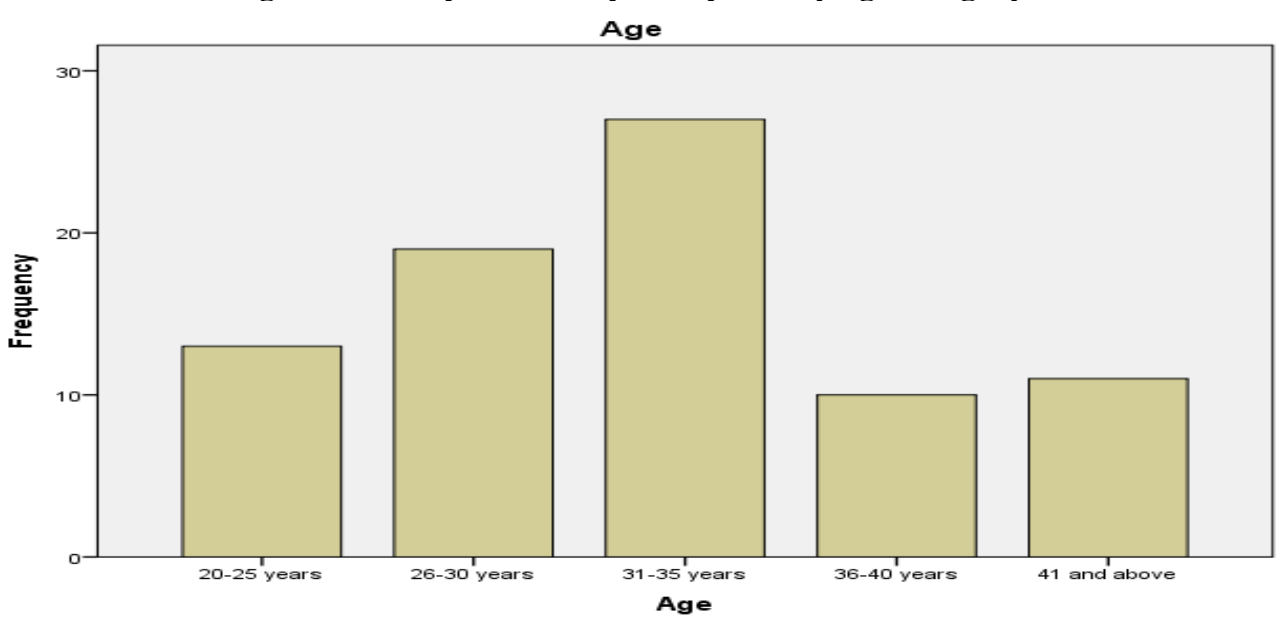


As the above figure 1 showed the respondents' $13(16.3 \%)$ are aged between 20 to 25 years old, $19(23.8 \%)$ are aged between 26 to 30 years old, 27 (33.8\%) are aged between 31 to 35 years old, 10 (12.5\%) are aged between 36 to 40 years old and $11(13.8 \%)$ are 41 and above years old. Thus, respondents' have a mean age of 2.84 and standard deviation of 1.247 years old.

Figure 2: compositions of participants by teaching experience

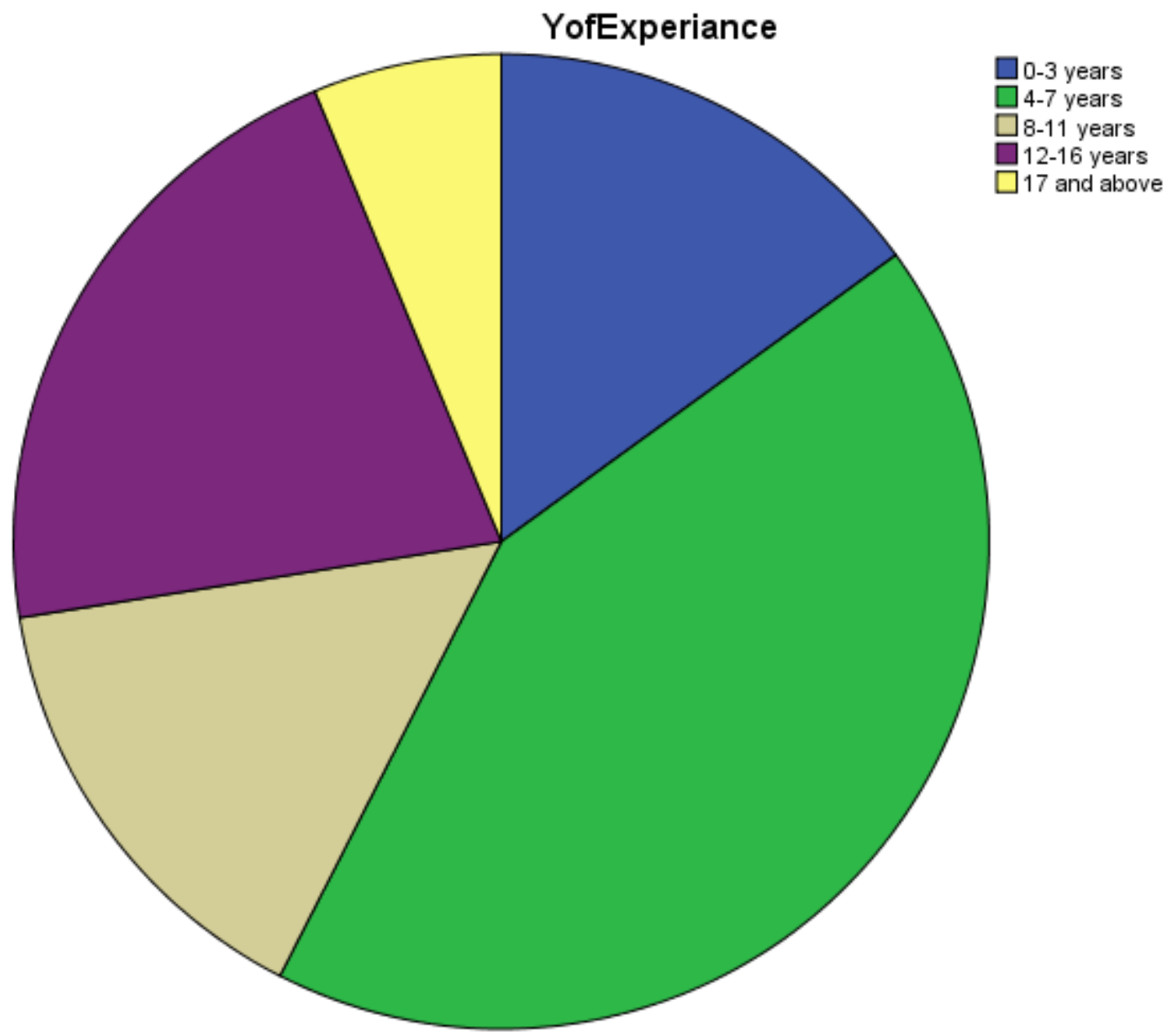

Figure 2 discloses that $12(15.0 \%)$ teachers have 0 to 3 years of service, $34(42.5 \%)$ teachers have 4 to 7 years of service, $12(15.0 \%)$ teachers have 8 to 11 years of service, $17(21.3 \%)$ teachers have 12 to 16 years of service and Some $5(6.3 \%)$ of them 17 and above year of teaching experience have a mean years of experience 2.61 and standard deviation of 1.164 .

Table 2: mean and standard deviation of perceptions of teachers

\begin{tabular}{|c|c|c|c|c|}
\hline № & \multirow{2}{*}{ Statement } & \multirow[b]{2}{*}{$\mathrm{N}$} & \multirow[b]{2}{*}{ Mean } & \multirow[b]{2}{*}{ Std. Deviation } \\
\hline & & & & \\
\hline 1 & Assessment makes students concentrate their efforts in learning & 80 & 4.31 & 0.866 \\
\hline 2 & Assessment makes students confident for their final examination & 80 & 4.31 & 0.789 \\
\hline 3 & Assessment makes it difficult for teachers to cover the course. & 80 & 2.84 & 1.345 \\
\hline 4 & Assessment has minor impact on teaching and learning & 80 & 2.84 & 1.107 \\
\hline 5 & Assessment feedback is useful in enhancing students' performance & 80 & 4.46 & 0.635 \\
\hline 6 & Assessment increases the workload for teachers & 80 & 3.21 & 1.429 \\
\hline 7 & Continuous assessment is time consuming & 80 & 3.44 & 1.271 \\
\hline
\end{tabular}

Table 2 shows that teachers had highly favorable perceptions of the role of assessment in making students: concentrate their efforts in learning (Mean $=4.31, \mathrm{~S} . \mathrm{D}=0.866)$ and confident in their final examinations $($ Mean $=$ 4.31 , S.D $=0.789$ ). Their perception on a statement that assessment feedback is useful in enhancing students' performance was favorably high with a mean of 4.46 and such views tend to consider assessment as a burden for them rather than an important tool which generates useful information for enhancing both teaching and learning. The percentages of responses given by respondents for each of the perception statements contained in the 
questionnaire are presented in Table 3.

Table 3: Teachers' perceptions on continuous assessment

\begin{tabular}{|c|c|c|c|c|c|c|c|c|c|c|c|}
\hline № & \multirow[t]{2}{*}{ Statement } & \multicolumn{2}{|c|}{ SD } & \multicolumn{2}{|l|}{$\mathrm{D}$} & \multicolumn{2}{|l|}{$\mathrm{U}$} & \multicolumn{2}{|l|}{$\mathrm{A}$} & \multicolumn{2}{|c|}{ SA } \\
\hline & & $\mathrm{f}$ & $\%$ & $\mathrm{~F}$ & $\%$ & $\mathrm{~F}$ & $\%$ & $\mathrm{f}$ & $\%$ & $\mathrm{f}$ & $\%$ \\
\hline 1 & $\begin{array}{l}\text { Assessment makes students } \\
\text { concentrate their efforts in learning }\end{array}$ & 0 & 0 & 7 & 8.8 & 0 & 0 & 34 & 42.5 & 39 & 48.8 \\
\hline 2 & $\begin{array}{l}\text { Assessment makes students } \\
\text { confident for their final examination }\end{array}$ & 0 & 0 & 2 & 2.5 & 10 & 12.5 & 29 & 36.3 & 39 & 48.8 \\
\hline 3 & $\begin{array}{l}\text { Assessment makes it difficult for } \\
\text { teachers to cover the course. }\end{array}$ & 15 & 18.8 & 26 & 32.5 & 4 & 5.0 & 27 & 33.8 & 8 & 10 \\
\hline 4 & $\begin{array}{l}\text { Assessment has minor impact on } \\
\text { teaching and learning }\end{array}$ & 9 & 11.3 & 28 & 35.0 & 11 & 13.8 & 31 & 38.8 & 1 & 1.3 \\
\hline 5 & $\begin{array}{l}\text { Assessment feedback is useful in } \\
\text { enhancing students' performance }\end{array}$ & 0 & 0 & 0 & 0 & 6 & 7.5 & 31 & 38.8 & 43 & 53.8 \\
\hline 6 & $\begin{array}{l}\text { Assessment increases the workload } \\
\text { for teachers }\end{array}$ & 13 & 16.3 & 16 & 20.0 & 11 & 13.8 & 21 & 26.3 & 19 & 23.8 \\
\hline 7 & $\begin{array}{l}\text { Continuous assessment is time } \\
\text { consuming }\end{array}$ & 11 & 13.8 & 8 & 10.0 & 9 & 11.3 & 39 & 48.8 & 13 & 16.3 \\
\hline
\end{tabular}

The results of item 1 in table 3 , showed that most of the respondents 39 (48.8\%) strongly agreed and 34 $(42.5 \%)$ agreed that they have good feeling towards continuous assessment makes students concentrate their efforts in learning. on the other hand, few of them $7(8.8 \%)$ of them disagreed that they have not good feeling towards continuous assessment makes students concentrate their efforts in learning.

For item 2, majority of the respondents $68(85.1 \%)$ agreed that assessment makes students confident for their final examination. But minority of them $2(2.5 \%)$ disagree the idea that assessment makes students confident for their final examination. and few of the respondents $10(12.5 \%)$ did not show the agreement or disagreement in the statement.

In line with this, respondents' response for item 3 majorities of the respondents $41(51.3 \%)$ disagreed that assessment makes it difficult for teachers to cover the course. However, 35 (43.8\%) of respondents agreed that assessment makes it difficult for teachers to cover the course and some of them $4(5.0 \%)$ did not show the agreement or the disagreement on the issue.

Item 4 of table 3 showed that, Greater part of the respondents $37(46.3 \%$ ) disagreed that assessment has minor impact on teaching and learning, and 32 (33.6\%) agreed that assessment has minor impact on teaching and learning and the remaining are undecided.

From table 3, item 5 result showed that almost all $74(92.6 \%)$ of the respondents agreed that assessment feedback is useful in enhancing students' performance. But, some of them $6(7.5 \%)$ are undecided on the issue.

Item 6 in the same table, 40(50.1\%) respondents agreed on the statement assessment increases the workload for teachers' .Similarly, 29(36.3\%) disagreed on the statement assessment increases the workload for teachers'. and some of them are undecided did the idea.

Lastly, item 7, majority of the respondents $52(65.1 \%)$ agreed on the statement continuous assessment is time consuming. Similarly, minority of the respondents $19(23.8 \%)$ disagreed on the statement continuous assessment is time consuming and some of them undecided on the idea.

\section{B. Gender Differences in Perceptions}

The mean scores for male and female teachers were computed to determine whether there were gender differences in their perceptions. Table 4 presents the mean perception by female teachers had more favorable perceptions of assessment than their male counterparts.

Table 4 Teachers' Perception by Gender

\begin{tabular}{|ll|l|l|l|l|}
\hline & Sex & $\mathrm{N}$ & Mean & Std. Deviation & Std. Error Mean \\
\hline \multirow{2}{*}{ perception } & $\mathrm{F}$ & 23 & 4.11 & .572 & .119 \\
& $\mathrm{M}$ & 57 & 3.44 & .506 & .067 \\
\hline
\end{tabular}

In order to establish whether the observed differences in the mean perception score for male and female was statistically significant, an independent sample t-test was performed. The results of the t-test are presented in Table 5. 
Table 5: Gender Differences in Teachers' Perceptions

\begin{tabular}{|c|c|c|c|c|c|c|c|c|c|c|}
\hline & \multicolumn{2}{|c|}{$\begin{array}{l}\text { Levene's } \\
\text { Test for } \\
\text { Equality of } \\
\text { Variances }\end{array}$} & \multicolumn{7}{|c|}{ t-test for Equality of Means } \\
\hline & & \multirow[t]{2}{*}{$\mathrm{F}$} & \multirow[t]{2}{*}{ Sig. } & \multirow[t]{2}{*}{$\mathrm{t}$} & \multirow[t]{2}{*}{ df } & \multirow[t]{2}{*}{$\begin{array}{l}\text { Sig. (2- } \\
\text { tailed) }\end{array}$} & \multirow[t]{2}{*}{$\begin{array}{l}\text { Mean } \\
\text { Difference }\end{array}$} & \multirow[t]{2}{*}{$\begin{array}{l}\text { Std. Error } \\
\text { Difference }\end{array}$} & \multicolumn{2}{|c|}{$\begin{array}{l}95 \% \text { Confidence } \\
\text { Interval of the } \\
\text { Difference }\end{array}$} \\
\hline & & & & & & & & & Lower & Upper \\
\hline \multirow{2}{*}{ perception } & $\begin{array}{l}\text { Equal } \\
\text { variances } \\
\text { assumed }\end{array}$ & \multirow[t]{2}{*}{.544} & \multirow[t]{2}{*}{.463} & 5.141 & 78 & .000 & .667 & .130 & .409 & .925 \\
\hline & $\begin{array}{l}\text { Equal } \\
\text { variances not } \\
\text { assumed }\end{array}$ & & & 4.877 & 36.645 & .000 & .667 & .137 & .390 & .944 \\
\hline
\end{tabular}

The significance level of Levene's Test value $p=0.463$ is greater than the cut-off 0.05 the assumption of variance for the two groups of males and females are the same. Since the value in Sig. (2-tailed) in equal variances assumed is less than or equal to the cut-off 0.05 then there is a significant difference in the mean scores of the dependent variable for each of the two groups of males and females.

Results presented in Table 5 shows that there is a statistically significant difference in teachers' perception of assessment by gender. The $t$-test indicates that female teachers had more favorable perceptions of assessment than male teachers

Table 4 and 5 are the output of SPSS when we take the aggregate mean of the seven questionnaires items. Then, to combine the above two tables for a standard analysis we would have table 6 as follows.

\begin{tabular}{llllllll}
\hline item & Sex & N & mean & SD & T & Df & sig. \\
\hline perception & F & 23 & 4.11 & 0.572 & 4.877 & 78 & .000 \\
& M & 57 & 3.44 & 0.506 & & & \\
\hline
\end{tabular}

There is a significance mean difference between perception of male and female teachers $(\mathrm{M}=4.11, \mathrm{~F}=3.44)$. And the independent $t$-test shows there is a significance perception difference between male and female $(t=4.877$, $\mathrm{df}=78, \mathrm{p}=.000)$.

C. General Perception towards continuous assessment practices

The questionnaire was analyzed to find out mathematics teachers attitude towards practices of continuous assessment. Table 7 shows the criteria used to categorize these variables as low, medium and high, based on the range of scores as cited by [10], [11].

Table 7: Level of Variables

\begin{tabular}{|l|l|}
\hline Mean Score & Level \\
\hline $1.00-2.33$ & Low \\
\hline $2.34-3.66$ & Medium \\
\hline $3.67-5.00$ & High \\
\hline
\end{tabular}

Table 8: Respondents' overall response on perception towards practices of continuous assessment

\begin{tabular}{|l|l|l|l|}
\hline & Mean & Std. Deviation & Variance \\
\hline Perception & 3.630 & 1.063 & 1.210 \\
\hline
\end{tabular}

As can be seen in table 10, the general respondents' perception towards continuous assessment has mean 3.630 and standard deviation 1.063. Therefore, Using Table 8, this mean lies 2.34 - 3.66 means score which is medium attitude and attention should be given to the perception of teachers. if continuous assessment is practiced and teachers must understand the assessment process and accept is as their own for its effective implementation. In spite of this fact, lack of orientation and assistance from the concerned individuals, inadequate training and lack of adequate materials make it difficult for teachers to appreciate and apply continuous assessment.

\section{CONCLUSION AND RECOMMENDATION}

A. Conclusion

The main purpose of this study was to examine the perceptions of Secondary School Mathematics Teachers on the use of continuous assessment in Guraghe Zone.

The study was proposed two main research questions.

1. What is the perception of mathematics teachers towards continuous assessment?

2. What are significant differences in teachers' perceptions of assessment by gender? 


\section{The major findings of this study were:}

$>$ Most of the respondents 39 (48.8\%) strongly agreed and 34 (42.5\%) agreed that they have good feeling towards continuous assessment makes students concentrate their efforts in learning. on the other hand, few of them $7(8.8 \%)$ of them disagreed that they have not good feeling towards continuous assessment makes students concentrate their efforts in learning.

$>$ Majority of the respondents $68(85.1 \%)$ agreed that assessment makes students confident for their final examination. In line with this $41(51.3 \%)$ disagreed that assessment makes it difficult for teachers to cover the course.

$>$ Greater part of the respondents 37(46.3\%) disagreed that assessment has minor impact on teaching and learning, and $32(33.6 \%)$ agreed that assessment has minor impact on teaching and learning and the remaining are undecided.

$>$ Almost all $74(92.6 \%)$ of the respondents agreed that assessment feedback is useful in enhancing students' performance and 40(50.1\%) respondents agreed on the statement assessment increases the workload for teachers' . Lastly, majority of the respondents 52(65.1\%) agreed on the statement continuous assessment is time consuming. Similarly, minority of the respondents $19(23.8 \%)$ disagreed on the statement continuous assessment is time consuming and some of them undecided on the idea

$>$ In general, over all respondents' attitude towards word problem solving has mean 3.09 and standard deviation 1.210. Therefore, these mean lies 2.34 - 3.66 means score which is medium attitude.

\section{B. Recommendation}

Based on the above conclusion, the researchers suggest the following possible measures should be taken so that the present problem concerning practices of the implementation of continuous assessment in zone could be minimized.

\& The zone or the each secondary school should create conducive environment and give support by arranging and giving training for teachers in order to increase and develop their positive attitude towards practices of continuous assessment.

\& Practicing continuous assessment in class room has a great importance for students since they devote their time in academic issue and they share their knowledge with each other.

\& Teachers' attitude has its own impact on students' attitude. So, teachers' should have positive attitude and encourage themselves to study and practice about continuous assessment.

$\$$ Secondary school teachers should get additional training and awareness how they implement continuous assessment.

\& The curriculum on the teachers' text book or guide must include the solution of some problems to make the teachers confidential.

* The parents must give advice for their children to be disciplined and respect their teachers.

* Finally, further research should be conducted on a zone including all secondary schools science teachers since it could be difficult to generalize the current finding to all teachers of the zone.

\section{REFERENCE}

[1] A. J. Nitko and S. M Brookhart, Educational Assessment of Students, 5th ed., Upper Saddle River, NJ: Merril, 2007, p. 4.

[2] T. A. Angelo and P. K. Cross, Classroom Assessment Techniques: A Handbook for College Teachers, 2nd ed., San Francisco: Jossey-Bass, 1993, pp. 3-7.

[3] M. B Huba and J. E Freed, Learner-centered assessment on college campuses: Shifting the focus from teaching to learning, Boston: Allyn and Bacon, 2000, ch. 1.

[4] W. J. Popham, Classroom Assessment: What Teachers Need to Know, 5th ed., Boston: Allyn and Bacon, 2008, pp. 12-16.

[5] Segers, M., Dochy, F. \& Cascallar, E. (eds). (2003). Optimising New Modes of Assessment: In Search of Qualities and Standards. Kluwer Academic Publishers, Dordrecht.

[6] R. Linn and N Gronlund, Measurement and Assessment in Teaching, 8th ed., Upper Saddle River, NJ: Merrill, 2000.

[7] Greaney V (2001). Using Assessment to improve the quality of Education Paris: UNESCO International Institute for Education Planning.

[8] Webb N, Briars D (1990). Assessment in Mathematics Classroom, k-8 in T.J. Cooney (ed.), Teaching and learning Mathematics in the 1990s, 1990 Yearbook of the National Council of Teachers of Mathematics, Reston VA.

[9] Teshome Demisse, 2001. Assessment of Pupils' Achievement in the Teaching of English: Training and Practice in focus. The Ethiopian Journal of Education. 21(1), 25-47. Urevbu, A., 1999. Curriculum Studies. Singapore: Longman

[10] Lawsha Mohamed (2011) Secondary Students' Attitude towards Mathematics in a Selected School of 
Maldives Lawsha Mohamed Institute of Education International Islamic University Malaysia.

[11] Lemi M. Habetamu S (2017) Examining Mathematics teachers' use of Modeling Approaches for Solving Word Problems in Secondary Schools of Benshangul Gumuz Region, College of Natural and Computational Science, Department of Mathematics, Assosa University, Ethiopia, Applied Vol. 4, Issue 2, Dec 2017, 1-6 